\title{
Comunicação no ensino, na aprendizagem e na atividade profissional do professor de Matemática: implicações da Didática Profissional (DP)
}

\author{
Communication in the teaching, learning and professional activity of the Mathematics teacher: \\ implications of Professional Didactics (DP)
}

Francisco Regis Vieira Alves

Nadja Maria Acioly-Régnier

\begin{abstract}
RESUMO
O presente trabalho apresenta uma discussão sobre a comunicação, sobre sua relevância estratégica, tanto no ensino e na aprendizagem, todavia, com ênfase declarada pelo papel e atividade do professor de Matemática. De fato, registramos vários trabalhos no Brasil que abordam as interações comunicativas necessárias para a transmissão do saber matemático, entretanto, pouco se menciona sobre a aprendizagem do professor de Matemática, diante de situações profissionais e a aquisição de habilidades adequadas para uma significativa troca de interações comunicativas com os estudantes. Dessa forma, ao assumir determinados pressupostos e um viés de análise amparado pela vertente francesa da Didática Profissinal (DP), o trabalho discute a noção de competência profissional do professor e o emprego de gestos profissionais imprescindíveis para o desempenho de qualquer atividade laboral. Por fim, se registra um exemplo no ensino de Matemática, relativamente à noção de integral generalizada, em que, as interações comunicativas são condicionadas pela interação com a tecnologia e uso de software e se constata a ocorrência de gestos que carregam e transmitem o significado de conceitos científicos matemáticos.

Palavras-chave: comunicação e ensino; professor de Matemática; competência profissional; aprendizagem do professor; comunicação gestual.
\end{abstract}

\section{ABSTRACT}

This paper presents a discussion about communication, its strategic relevance in teaching as well as learning, however, emphasizing the role and activity of the Mathematics teacher. In fact, we report several works in Brazil that address the communicative interactions necessary for the transmission of mathematical knowledge, however, little is mentioned about the Mathematics teacher's learning, in face of professional situations and the acquisition of appropriate skills for a meaningful exchange of interactions. Thus, certain assumptions and an analysis bias supported by the French research of Professional Didactics (PD), the paper discusses the notion of professional competence of the teacher and the use of professional gestures which are essential for the performance of any work activity. Finally, there is an example related to the teaching of Mathematics, regarding the notion of generalized integral, in which communicative interactions are conditioned by interaction with technology and software use and the occurrence of gestures that carry and convey the meaning of mathematical scientific concepts.

Keywords: communication and teaching; Math teacher; professional competence; teacher's learning; gestural communication. 


\section{INTRODUÇÃO}

No Brasil registramos alguns estudos acadêmicos acerca dos fenômenos derivados do processo de comunicação do conhecimento matemático. A função do processo de comunicação, desde que bem apreciada pelo professor de Matemática, possui um papel estratégico e imprescindível para a interação adequada e a construção correspondente dos conhecimentos científicos. Grande parte dos episódios mais visíveis, em que, podemos vislumbrar a importãncia da comunicação e da linguagem envolve situações didáticas, visando o desenvolvimento de certas lições e das tarefas regulares concebidas e propostas pelo professor de Matemática aos estudantes.

Nesse contexto, o professor de Matemática busca, de forma precípua, o desenvolvimento de habilidades matemáticas que ocorrem, quer sejam elas do ponto de vista verbal, oral, da escrita e, acrescentamos, de natureza e forma gestual. Aqui, divisamos um papel estratégico da tecnologia atual e, mais precisamente, da utilização de softwares de Matemática, que potencializam determinadas situações de comunicação e tornam visível e/ou perceptível os multifacetados processos de aprendizagem da interação dos estudantes e professor com a tecnologia.

Por outro lado, no presente trabalho, buscaremos discutir um outro viés do cenário descrito há pouco. De fato, no Brasil (Machado, 2003) e em outros países (Coulange, 2014; Riccomini, Smith, Hughes \& Fries, 2015), quando discutimos o ensino de Matemática, de imediato, o papel do estudante assume única relevância central. Entretanto, quando mencionamos aqui o fenômeno da comunicação, da efetiva compreensão das interações comunicativas envolvendo o trinômio clássico "estudantes-professor-saber matemático", não podemos desconsiderar a adequada competência profissional do professor, diante do exercício de suas atividades ordinárias e regulares na docência, como sendo um fator determinante para a evolução satisfatória de qualquer processo fundamental de comunicação e, portanto, de aprendizagem do professor de Matemática, mediante o desenvolvimento de suas atividades profissionais.

Francisco Regis Vieira Alves. Professor Titular do Instituto Federal de Educação, Ciência e Tecnologia do Estado do Ceará, departamento de Matemática e Física, Brasil. Bolsista de Produtividade em Pesquisa do Conselho Nacional de Desenvolvimento Científico e Tecnológico - CNPQ/PQ2. Docente Permanente do Mestrado Acadêmico em Ensino de Ciências e Matemática - PGECM/IFCE. Docente Permanente do Mestrado Profissional em Educação Profissional e Tecnológica - ProePT/IFCE em Rede. Docente Permanente do Doutorado em Rede Região Nordeste - Renoen. Correio eletrônico: fregis@ifce.edu.br. ID: https://orcid.org/0000-0003-3710-1561.

Nadja Maria Acioly-Régnier. École Supérieure du Professorat et de l’Éducation de l’Académie de Lyon, França. Possui graduação em Psicologia pela Universidade Federal de Pernambuco (1981), mestrado em Psicologia Cognitiva pela Universidade Federal de Pernambuco (1985), Diploma de Estudos Aprofundados (D.E.A.) em Psicologia pela Université René Descartes Paris V Sorbonne (1989) e doutorado em Psicologia pela mesma universidade em 1994. Possui Habilitation à diriger des recherches pela Université Lumière Lyon 2 - France, em 2010. Pesquisador da Equipe d’Accueil 4571 Éducation, Cultures, Politiques e pesquisadora associada da UMR 5191 ICAR - Interactions, Corpus, Apprentissage, Représentations. Correio eletrônico: nadja. acioly-regnier@univ-lyon1.fr. ID: https://orcid.org/0000-0002-2730-9687. 
Dessa forma, assinalamos um ponto de vista importante derivado da vertente francesa de Didática Profissional (DP), cujo terreno de convergência cientítifica de determinadas áreas investigativas, e que declara interesse pelos processos de aprendizagem dos adultos no campo do trabalho, na formação e no exercício do ofício. De forma particular, em nossos trabalhos (Alves, 2018, 2019, 2020, 2021), assinalamos algumas implicações e repercussões de alguns dos pressupostos da DP, cujo pensamento é extensão natural do emblemático ponto de vista piagetiano, por intermédio da Teoria da Conceptualização da Ação (Vergnaud, 2007), possibilitando um expediente diferenciado para um exame minucioso do processo de aquisição da noção de competência profissional e um exame dos fenômenos da aprendizagem do adulto, mediante o desenvolvimento de atividades especializadas ao longo de toda a sua vida profissional.

Isso posto, nas seções vindouras, indicaremos alguns pressupostos da DP, assinalando uma natureza essencialmente de base cognitivista, e objetivando o entendimento da atividade profissional e dos processos de aprendizagem dela subjacentes. Em seguida, demarcaremos discussão pertinente sobre a aprendizagem, competência profissional e o interesse da DP, tendo em vista uma especial consideração pelos gestos profissionais, pela linguagem e pela comunicação profissional requerida no contexto da atividade. Em seguida, a partir de um cenário que objetiva a noção de competência profissional, sublinharemos que a aprendizagem em determinadas disciplinas científicas e, de modo particular e especial, da Matemática, não permite desconsiderarmos a importãncia de linguagens particulares, dos gestos (profissionais) do professor de Matemática e das possibilidades e ressignificações provocadas pela tecnologia.

Na seção subsequente discutiremos alguns pressupostos da Didática Profissional DP, diferenciando-a de outros campos de estudos característicos da Didática das Disciplinas específicas (Joshua \& Dupin, 1993). Mostraremos que determinados processos envolvendo os fenômenos de interações comunicativas não podem ser interpretados e/ou compreendidos apenas no interior da sala de aula. Ademais, um modelo metafórico e comparativo entre o professor iniciante (debutante) e o professor expert se mostrará bastante auspicioso em nossa discussão, tendo em vista o entendimento da noção de competência profissional e sua dimensão pragmática.

\section{Alguns pressupostos da Didática Profissional (DP)}

Segundo Pastré, Mayen e Vergnaud (2006), a vertente francesa da Didática Profissional, originada e constituida como campo de investigação científica na França, ao decurso dos anos 1990, manifesta interesse especial pela formação profissional e pelos processos de aprendizagem do e no trabalho. Pastré, Mayen e Vergnaud (2006) comentam que em um contexto de convergência e da contribuição de três vertentes de europeias de estudo (Psicologia do Trabalho, Ergonomia e Teoria da Conceptua- 
lização da Ação), a DP assume um interesse pela formação profissional e, de forma emblemática pelo trinômio "atividade-aprendizagem-formação", na medida em que:

É um campo de práticas que consiste em construir os dispositivos de formação correspondentes às necessidades identificadas para um público conhecido, em seu conjunto ou ambiente de trabalho. A formação escolar possui a tendência em descontextualizar as aprendizagens. A Engenharia de Formação irá insistir, ao contrário, sobre o contexto social no qual se deve efetuar uma aprendizagem de adultos em formação. Pois, tais adultos são, de modo inicial, pessoas que trabalham e, quando decidem realizar uma formação, a mesma é habitualmente conveniente ao trabalho, e não a partir de recortes disciplinares que, geralmente não possuem sentido para os mesmos [Pastré, Mayen \& Vergnaud, 2006, p. 147].

Cabe observar e, também, distinguir investigações desenvolvidas em campos epistêmicos disciplinares clássicos, como o caso da vertente francesa da Didática da Matemática, cujos fenômenos de ensino e aprendizagem são marcadamente afetados e condicionados por uma espécie de "contágio epistemológico" do saber técnico-científico de referência e, neste caso, o saber matemático (savoir mathematique) que, segundo a cultura francófona, se distingue e diferencia do conhecimento matemático (connaissance mathematique) (Margolinas, 2015). Neste sentido, Pastré, Mayen e Vergnaud (2006) distinguem e demarcam o interesse de teorias que se atêm aos fenômenos de transposição de saberes científicos e que se diferenciam da DP, que se centra na aprendizagem da atividade profissional e na aprendizagem dela decorrente, posto que, a maior parte de nossas vidas, dedicamo-nos ao trabalho.

Pastré (2011) demarca, a seguir, o escopo de interesse da DP:

Da mesma forma, em seu ponto de partida, a Didática Profissional manifestou interesse em se diferenciar da Didática das Disciplinas que, por sua vez, se interessa pela transmissão e aquisição de saberes. A Didática Profissional se centra sobre a aprendizagem nas atividades. Ou, como veremos, ela assume como objeto não o saber, mas uma atividade que provoca consequências importantes. Podemos mencionar por último, um elemento para qualificar a Didática Profissional: ela assume como objeto o desenvolvimento dos adultos, agregado com a ideia forte de que a maior parte dos adultos encontram seu desenvolvimento no trabalho [Pastré, 2011, p. 84].

Como assinalamos em nossos trabalhos (Alves, 2018, 2019, 2020, 2021) determinadas semelhanças entre a vertente da Didática da Matemática (Margolinas, 2015) e a Didática Profissional, ambas com influências do pensamento piagetiano, adotam a noção de situação, como um cenário de modelização e a compreensão sobre a aquisição de conhecimento e a construção significativa, mediante a ação do sujeito. Pastré (2002) aponta a análise cognitiva da atividade do sujeito, em situação e diante do desenvolvimento de tarefas profissionais especializadas, como elementos organizadores, regulares e estruturantes da análise cognitiva da ação.

As situações não são mais reduzidas ao papel de exemplos, apenas ilustrando o desenvolvimento cognitivo do sujeito. Eles são analisados como tais e é a partir das características que os encon- 
tramos que podemos entrar na análise da atividade dos atores. Análise cognitiva do trabalho, análise do trabalho situado: essas são as duas características da análise do trabalho na didática profissional: você precisa passar pela análise da situação para obter acesso à compreensão da atividade. Mas é a análise da atividade que torna possível identificar os elementos organizacionais conceituais que os atores retêm da situação. O casal situação-atividade é o núcleo teórico central em torno do qual nossa análise é organizada [Pastré, 2002, p. 16].

A DP introduz um ponto de vista pioneiro segundo o interese pela aprendizagem do sujeito, diante do desenvolvimento de atividades condicionadas no trabalho. Ademais, a partir de um rompimento com o pensamento tayloriano, segundo o qual, "a competência se constitui em saber executar e não saber compreender" (Pastré, 1999, p. 16). Por conseguinte, a noção de competência profissional adquire um outro viés histórico-social, um viés essencialmente ampliado de apreciação e de análise, como observamos no trecho seguinte.

A representação que temos do conceito de competência depende muito da história. Durante o período em que o taylorismo reinou supremo, ser competente era saber executar. Isso é encontrado em vários repositórios, muitos dos quais foram projetados na época. A competência é definida de maneira muito comportamental pelo desempenho alcançado. Não estamos tentando descobrir como o desempenho é alcançado, ou seja, como a ação é organizada. Apenas o resultado parece ter importância, de acordo com a fórmula ritual que declina a tarefa a ser executada em uma série de objetivos: ser capaz de ... (aqui para a habilidade) + a declaração de um objetivo preciso (aqui para a performance). Obviamente, na prática, o trabalho taylorizado não pode ser reduzido à sua dimensão processual [Pastre, 2001, p. 4].

Podemos constatar nas ponderações acima de Pastré (2001) um processo de transição da noção de competência profissional, que deixa de representar apenas a capacidade de cumprir tarefas e cumprimento de objetivos e, ao longo do tempo, passa a representar, como uma capacidade local e global de avaliação e resolução de problemas, bem como, a necessidade de compreensão dos elementos responsáveis pela organização da ação.

Ademais, com origem nos pressupostos da DP adquirimos e passamos a considerar elementos de natureza cognitivista e um exame não reducionista e simplificacionista das habilidades necessárias para o desenvolvimento de atividades laborais.

Por outro lado, desde que objetivamos o papel do professor de Matemática, na seção subsequente, situaremos algumas implicações oriundas da DP visando um exame cognitivista dos fenômenos relacionados com a comunicação e da linguagem matemática. Como mencionamos nos parágrafos predecessores, podemos identificar pesquisas que manifestam interesse pelo papel dos estudantes na aprendizagem da Matemática, entretanto, nossa atenção voltar-se-á para a aprendizagem do professor, diante de situações profissionais que se relacionam, ainda, com sua competência profissional. 


\section{ComunicaÇÃo, gestos E LiNGUAGEM NO TRABaLHO do PROFESSOR}

A DP desenvolve um interesse profundo pela trajetória envolvendo profissionais iniciantes (debutantes no ofício) dos profissionais mais experientes. Neste sentido, as estratégias e os sistemas de regulação de atividade de um profissional experiente (ou do professor expert) se distingue bastante. Por exemplo, quando consideramos a função de documentos oficiais que devem ser observados e seguidos, quer seja numa empresa ou em uma instituição escolar, observamos um viés lacônico dos experts. De fato, "tendo em vista que as prescrições concernem a um processo que comporta várias sequências possíveis de operações, a linearidade de um texto constitui uma fonte de dificuldade" (Leplat, 2004, p. 2002).

Nesse âmbito é que se evidencia o conteúdo pragmático dos conhecimentos dos sujeitos mais experientes (dos experts), visto que, seus domínios correspondentes dos documentos normativos lhes permitem "driblar" a aparente linearidade e a ortodoxia burocrática. Pouco mais adiante, Leplat $(2001,2004)$ indica um outro viés importante dos conceitos pragmáticos. De fato, Leplat (2004, p. 202) recorda que "o vocabulário técnico, administrativo, frequentemente, a inteligibilidade de regras oriundas de tais domínios permitem sua aplicação correta aleatória".

Por conseguinte, as abreviações, os códigos (profissionais) e os jargões, frequentemente utilizados em determinado métier, devem ser precisamente definidos e lembrados, notadamente, pelo intermédio do uso previsto". Aqui, assinalamos que o processo de "codificação" ou o uso de "jargões profissionais" confirma, em muitos casos e circunstâncias do trabalho, um maior significado profissional próprio, determinante, sobretudo, para os profissionais (e professores) mais experientes (os experts).

Em nosso segundo exemplo que busca evidenciar a relevância do componente pragmático ao decurso da vida profissional e que atua como elemento indicador do próprio processo evolutivo de especialização, trazemos o caso do estudo de Leplat (2013) acerca da noção do uso dos gestos em situação de trabalho e, ainda, no âmbito de interesse para a DP. Logo de imediato, o próprio autor confirma uma natureza difícil de demarcação, tendo em vista um campo ampliado de significações vinculadas com a noção de gesto. Tendo em vista seu intento de delimitar o campo e o objeto de estudo, Leplat (2013, p. 3) explica que "para fornecer uma definição precisa na presente investigação, propomos a definição seguinte: um gesto é um movimento humano ao qual é atribuído uma significação".

De imediato, segundo sua definição, compreendemos que a significação de um "gesto" dependerá de um quadro de referência social ou campo profissional (Mayen, Olry \& Pastré, 2017) e, em nosso caso de maior interesse, circunstanciado pela atividade do professor de Matemática. Leplat (2013, p. 4) proporciona, por exemplo, uma categorização para a referida noção, quando distingue os elementos: gestos-signos e gestos-ações. 
Reparemos, todavia, que mesmo não de forma imediata ou perceptível, a função dos gestos profissionais e dos jargões constituem elementos definidores de uma estabilidade e identidade profissional e que, recorrentemente, são partilhados no contexto da docência, por parte de professores atuantes, por vezes, em um determinado posto de trabalho ou atividade de ensino.

Ademais, no bojo do contexto da discussão das funcionalidades dos gestos, Leplat (2013) assinala: a funcionalidade expressiva e de comunicação; a funcionalidade instrumental e da funcionalidade cognitiva. A funcionalidade dos gestos como objeto de comunicação tem sido objeto de vários estudos, segundo o autor, cuja natureza faz referência às situações de trabalho. Leplat (2013, p. 4-5) explica que "as análises das atividades do trabalho relevam a existência de gestos-signos que são criados e explorados pelos operadores e que organizam o trabalho sob a forma de códigos verbais e imaginários".

Por sua vez, Leplat (2013, p. 4) assume o seguinte pressuposto: os gestos possuem funções particulares e cada gesto é portador de diferentes funções, cada uma dependendo do ambiente onde o gesto considerado é na atividade profissional. Decerto que, a depender a atuação profissional, “os gestos a análise da concepção de gestos e uso de códigos e sistemas gestuais, constituem uma parte bastante importante para a análise do trabalho" (Leplat, 2013, p. 5). O autor exemplifica determinadas situações em que os gestos-signos não prescritos correspondem a determinadas necessidades de comunicação instantânea e situacional no trabalho, todavia, sob um viés pragmático, não tomados, por vezes, formalmente em consideração e indicação de ações, diante de tarefas profissionais.

Leplat (2013, p. 6) produz uma importante categorização para os gestos-símbolos, quando esclarece e distingue a seguinte tipologia:

(a) a função referencial: que visa indicar uma informação sobre a referência do gesto;

(b) a função injuntiva: envolvendo os gestos visando produzir e requerer uma ação;

(c) a função fática: que envolvem os gestos visando mobilizar a atenção imediata dos destinadores;

(d) a função dêitica que designam um objeto ou mais geralmente uma situação e que busca localizar o fato no tempo sem defini-lo.

A despeito de sua função ou categorização, vale recordar que "certos gestos sugerem diretamente sua significação que pode ser compreendida antes mesmo de qualquer aprendizagem explícita” (Leplat, 2013, p. 6). Isso ocorrem, por exemplo, nos gestos com função fática ou dêitica, sobretudo, em certas profissões. Ademais, quando direcionamos nossa atenção à coletividade, podemos compreender que "os gestos podem ser considerados como uma forma de linguagem: a linguagem ges- 
tual" (Leplat, 2013, p. 6). Observamos, assim, um expediente necessário visando a compreensão de todo um amplo repertório de gestos profissionais adquiridos pelo professor de Matemática que, no decurso de sua vida profissional, tendem a adquirir, progressivamente, maior estabilidade e significado e proporcionam, por vezes, a aquisição de princípios de economia e simplificação das atividades no ensino. Tal característica, por exemplo, caracteriza e concorrem para a constituição de uma competência incorporada, de determinados significados compartilhados por um grupo profissional, pois são constituidas como habilidades e competências que se manifestam apenas por intermédio da ação (Pastré, 1999, p. 17).

Sobre o referido tema, Leplat (2013) assinala o interesse das pesquisas desenvolvida na área da DP, quando observa a função social dos gestos, quando menciona que:

As pesquisas que serão apresentadas são conduzidas em situação de trabalho, afim de analisar o papel dos gestos nas atividades de concepção coletiva. Os gestos colocados em destaque no caso são os mesmos utilizados ao decurso de discussões coletivas visando a elaboração de um projeto solução de um problema específico. Tratam-se de gestos que não são normalizados e que acompanham, espontaneamente o discurso, sendo, em geral, bem compreendidos pelos interlocutores [Leplat, 2013, p. 8].

Com origem do pensamento anterior, depreendemos que a noção de gesto profissional se insere de forma substancial e se verifica em qualquer atividade profissional. No caso do professor de Matemática, podemos registrar um conjunto de regras, nem sempre explicitas, que congregam, aproximam e, também, conferem determinada estabilidade e identidade profissional no exercício da docência, correspondentemente a um conjunto de individuos que partilham do mesmo ofício.

Por exemplo, o uso de "jargões" que, por vezes, acompanham a atividade de ensino e a atividade do professor, que ultrapassa os limites da sala de aula, podem ser identificados como características intrinsecas que distinguem, por exemplo, um professor de História ou Português de um professor de Matemática. A partir de um contexto de exame ampliado, percebemos que a linguagem, que carrega consigo um conjunto de juizos e valores pragmáticos do indivíduo, proporciona uma atividade e uma forma especializada de "agir", sobretudo, quando objetivamos situações características de trabalho.

Não podemos desconsiderar, entretanto, o aprendizado e a construção de conhecimento (matemático), dela decorrente. Com efeito, Coulange, Jaubert e Lhoste (2018) comentam que:

Qualquer sujeito que organize sua atividade de acordo com sua percepção do contexto em que é chamado a agir (Bruner, 1983), consideramos que a linguagem sinaliza o contexto em que está ancorada e que é uma ferramenta e reveladora de mudanças de contexto, inerentes à aprendizagem e construção de conhecimento [Coulange, Jaubert \& Lhoste, 2018, p. 65].

A partir da própria natureza da comunicação, até mesmo a comunicação envolvendo trocas e as interações derivadas do trinômio professor-estudantes-saber 
matemático, objetivamos a necessidade do emprego de teorias que proporcionam um ponto de vista diferenciado de fenômenos multifacetados. Nesse sentido, quando consideramos o papel dos gestos profissionais como, também, uma habilidade adquirida na atividade do professor, fazemos apelo ao campo da Ergonomia, como os autores Coulange, Jaubert e Lhoste (2018) atestam em seguida.

A noção de gesto profissional (GP), emprestada do campo da Ergonomia, surge em diferentes didáticas no momento em que os pesquisadores questionam o papel do professor nas situações de ensino-aprendizagem em matemática (Margolinas , 2005), em ciências (Larcher \& Schneeberger, 2007) e em francês (Bucheton, 2008). Não é mais possível continuar observando a atividade dos alunos em sala de aula independentemente da do professor, sem questionar sua articulação [Coulange, Jaubert e Lhoste, 2018, p. 66].

Quando objetivamos os fenômenos de comunicação, a linguagem adquire um papel proeminente. De fato, as interações do sujeito com o meio envolvem comportamentos prototípicos, característicos e condicionados por determinados viéses sociais. O papel da linguagem matemática não se mostra diferente. O professor de Matemática adquire um conjunto de representações mentais, mediante sua atuação no ensino, condicionadas pela natureza intrinseca dos conhecimentos, das atividades realizadas e do saber matemático. No decurso do tempo, sobretudo quando consideramos os professores de Matemática mais experientes, podemos registrar o incremento de um dicionário básico de informações e o uso da linguagem (profissional), recorrentemente acionados/empregados na sua atividade de ensino.

Clot e Faita (2000) expressam um ponto de vista globalizante, logo em seguida, sobre gênero e funcionamento da linguagem (e do dircurso) em um contexto social ampliado, todavia, com repercursão imediata para o nosso caso da nossa discussão particular.

Segundo ele, as relações entre sujeito, idioma e mundo não são diretas. Eles se manifestam nos tipos de discurso disponíveis que o sujeito deve ter para entrar na troca. "Se tivéssemos que criar cada uma de nossas declarações pela primeira vez na troca, essa troca seria impossível" (Bakhtin, 1984, p. 285). Esses gêneros fixam, em um determinado ambiente, o regime social do funcionamento da linguagem. É um estoque de declarações esperadas, protótipos das maneiras de dizer ou não dizer em um espaço-tempo sociodiscursivo. Podemos falar, com F. François, de protossignificações genéricas que conectam linguagem e não linguagem (1998, p. 9). Essas declarações retêm a memória impessoal de um ambiente social em que são autoritativas e dão o tom. Traem as insinuações que regulam as relações com objetos e entre pessoas, tradições adquiridas que são expressas e preservadas sob o envelope de palavras. Eles protegem o sujeito contra o uso inadequado de sinais em uma determinada situação. Um gênero está sempre ligado a uma situação no mundo social [Clot \& Faita, 2000, p. 10].

Observamos, por sua vez, que um estoque de declarações comunicadas por um professor de Matemática regulará, de forma esperada, um espaço-tempo sociodircursivo condicionado pelo uso da linguagem matemática. Nesse caso, um exame do 
regime social do funcionamento da linguagem do professor de Matemática se constitui um outro elemento a ser considerado no cotejo de sua competência profissional.

Nas seções predecessoras indicamos alguns pressupostos e elementos derivados da DP que detêm a possibilidade de compreendermos os fenômenos da comunicação, da função dos gestos e outros elementos portadores de significado, na medida em que acentuamos o papel do professor de Matemática e situações de aprendizagem a partir do e no trabalho.

\section{IMPLICAÇÕES SOBRE A COMPETÊNCIA PROFISSIONAL DO PROFESSOR DE MATEMÁTICA}

Em nossos trabalhos (Alves, 2018, 2019, 2020, 2021) identificamos três binômios característicos e fundamentais, os quais, tomamos como referência para a análise da noção de competência profissional do professor de Matemática. O primeiro binômio indicamos por "professor-estudantes". O segundo binômio fundamental envolve considerar "professor-professores" e, por fim, indicamos o binômio "professor-instituição escolar". De uma forma simplificada, podemos afirmar que os juízos a avaliações pragmáticas que recaem sobre a atividade do professor de Matemática se originam, basicamente, a partir das interações envolvendo os três binômios indicados há pouco.

Resgatamos um pensamento de Pastré (1999) quando este autor desenvolve uma análise da atividade de operários diante da manutenção e controle de máquinas. O autor declara que, boa parte do trabalho dos operários envolve se deparar com situações-problema. Pastré (1999) observa que problemas profissionais com determinado nível inicial de complexidade e relativamente previstos podem ser identificados/ resolvidos por operários com relativa ou pouca experiência inicial. Entretanto, diante da ocorrência de problemas inesperados, erráticos e inabituais, somente o estilo pragmático, plástico e de maior capacidade de adaptação dos operários experientes se mostra capaz de solucioná-los.

Ora, empregamos um pensamento metafórico semelhante, quando consideramos a atividade profissional do professor de Matemática. Concordamos com o pensamento de Pastré (1999, p. 18) quando observa a tênue e difusa relação entre a eficacidade na ação e os conceitos progmáticos (profissionais), pois, "eles possuem um modo de transmissão bastante específico, que mistura transmissão por imitação e mistura transmissão por linguagem". Dessa forma, quando tomamos como referência o professor de Matemática iniciante, debutante no ofício, podemos registrar uma série de atitudes e juízos pragmáticos que são transmitidos pelas trocas interpessoais, quer sejam com estudantes, quer sejam elas com os próprios colegas de trabalho. Para esses profissionais (os professores iniciantes), os limites de sua atividade, de sua ação e, por conseguinte, do exame de sua competência são intrinsecamente condicionados pelos limites de sua memorização e internalização de rotinas, de compreensão de normas técnicas e indicações originadas em documentos da instituição escolar. 
Por outro lado, observamos que a noção de competência profissional do professor de Matemática se evidencia, na medida em que, o mesmo se depara com problemas e situações inesperadas no seu contexto de atividade profissional. Para situações de atividade profissional inesperada como esta, Pastré (1999, p. 17) esclarece que "não se trata mais de uma aplicação de regras apropriadas para uma determinadas situação, se tratando de novas regras a partir de conceitos, fato que permite a compreensão considerável do repertório de regras". Reparemos, entretanto, que, em qualquer situação, o repertório de conhecimentos e de habilidades operacionais do professor de Matemática regulará e condicionará a qualidade de transmissão, julgamento, linguagem e a comunicação. Neste caso os fenômenos, as interações comunicativas podem tomar como referência, de forma direta, o saber matemático requerido e determinado pelo currículo escolar de determinada instituição, bem como, de forma indireta, os fenômenos envolvendo gestos e linguagens profissionais que proporcionam julgamentos sobre a atividade do professor de Matemática e, portanto, sobre sua competência profissional, de forma circunstanciada.

Por sua vez, Vergnaud (2007) revela o real teor e a natureza da noção de competência profissional. Sua descrição se apresenta irremediavelmente vinculada e condicionada pela noção de capacidade plástica adaptativa do indívíduo (trabalhador ou professor), diante de um conjunto de situações (profissionais) características e fundamentais para o exercício efetivo de um determinado métier e que conferem, de modo irremediável, um componente pragmático atinente à noção de "competência profissional em situação". Com efeito, o mesmo declara que:

O conceito de competência não é para mim um conceito científico, é um conceito pragmático e prático que é útil e que uso constantemente porque faço parte de uma comunidade humana na qual precisamos nos comunicar, incluindo com termos que não são aprendidos sistematicamente. Mesmo assim, vou falar sobre conceitos aprendidos, como esquemas, invariantes operacionais, conceitos em ato, teoremas em ato, porque, para treinadores de professores, esses são conceitos essenciais. Se eu quero estar operacional, preciso examinar as habilidades nas situações e, em particular, nas classes de situações. De fato, não somos competentes para uma situação singular, mas, em geral, para situações que pertencem a uma determinada classe, que têm certas características. Precisamos analisar a atividade em relação às características das situações [Vergnaud, 2007, p. 1].

A partir de um modelo metafórico de automatização do trabalho, podemos compreender que, atualmente, a eficiência ou competência do professor se origina de uma capacidade, cada vez mais tácita e substancial de agir e reagir aos incidentes não previstos e situações (problemas) escolares inéditas. Por conseguinte, podemos adquirir um entendimento de que ser competente significa a capacidade de gerenciar, cada vez mais, situações reconhecidamente complexas, erráticas e não triviais, todavia, recorrentes e invariantes no plano de um sistema escolar (ou instituição) e, de modo particularmente importante, no interior da sala de aula de Matemática.

Antes de finalizarmos, não podemos desconsiderar os desafios da tecnologia atual que se apresentam ao professor de Matemática, sobretudo, as velocidade de suas modifi- 
cações e suas exigências diárias correspontes. Neste sentido, não podemos negligenciar questões relativas à diversidade cultural, ao uso eficiente da tecnologia e aos recursos metodológicos e didáticos imprescindíveis para a atividade profissionai do professor de Matemática. Vejamos, mais uma vez, um trecho do pensamento de Leplat (2001) sobre a natureza de situações de comunicação. Tal fenômeno se constitui um objeto de interesse em Ergonomia e proporciona um outro ponto de vista de análise da interação ser humano-máquina e ser humano-computador.

As situações de comunicação são muito diversas e incluem não apenas as comunicações pessoais (orais, escritas, gestos etc.), mas também as comunicações entre o homem e os elementos do mundo em que ele está inserido. Dessa maneira, fomos capazes de falar, em Ergonomia, de comunicações homem-máquina ou homem-computador [Leplat, 2001, p. 3].

Aqui, mesmo de modo en passant, assinalamos a possibilidade de contribuição de vertentes de investigação, tais como a Ergonomia, que proporciona uma perspectiva sistemática dos fenômenos envolvendo interações homem-máquina e homem-computador. No caso particular do ensino de Matemática, exemplificamos nas figuras abaixo, as interações e a manifestação gestual que age como um amparo aos princípios de comunicação e transmissão de ideais matematicas, diante de situações de aprendizagem propostas pelo professor.

Antes de finalizarmos, não podemos desconsiderar que os elementos gestuais e verbais mobilizados nas figuras 1 e 2 (logo abaixo) refletem um processo de mediação do professor de Matemática. Neste caso, apesar de não discutirmos a miude tal temática, os conhecimentos profissionais do professor de Matemática envolvem um know all sobre a utilização de comandos do software GeoGebra, da modelização, concepção e construção de situações didáticas sobre o objeto matemático denominado por integral generalizada ou integral imprópria. A noção de competência profissional do professor poderá ser evidenciada, avaliada, por exemplo, quando comparada com a atividade proposta, por exemplo, de um outro professor de Matemática, que desenvolve trabalho didático sobre o mesmo conteúdo matemático, entretanto, desconsiderando a tecnologia atual (Riccomini et al., 2015).

A despeito do caráter abstrato e formal da noção de integral generalizada, o exemplo que ilustramos nas figuras 1 e 2 abaixo, o mesmo se apresenta bastante didático, na medida em que, diante de seu caráter formal e técnico-estruturante, quando consideramos a atividade do professor de Matemática que valoriza, em sua prática de ensino, o papel da intuição, da percepção e da comunicação, tendo em vista a promoção de um cenário de aprendizagem significativa, temos a posssibilidade de registrar formas alternativas de comunicação e troca de significados, de ideias entre estudantes e entre professor-estudantes.

Nas figuras 1 e 2 Lima (2017) abordou uma situação envolvendo a noção e compreensão do processo de convergência ou divergência de uma integral generalizada. 
Podemos identificar o caratér pragmático dos significados transmitidos pelos estudantes, na medida em que a mediação didática do professor de Matemática estimula o desenvolvimento de um cenário de aprendizagem e de cooperação, envolvendo a interação professor-estudante-computador.

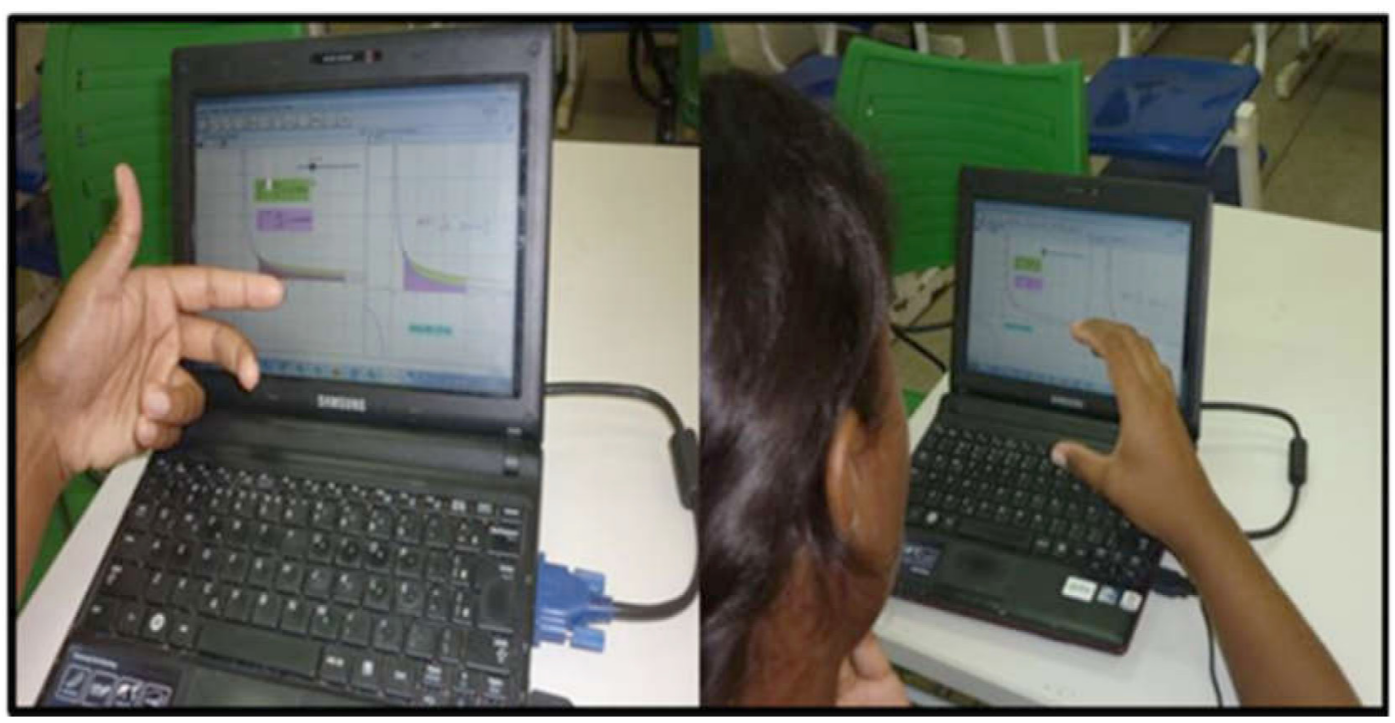

Figura 1. Descrição de um cenário de aprendizagem envolvendo a noção de Integral Generalizada e o papel dos gestos dos estudantes. Fonte: Lima, 2017.

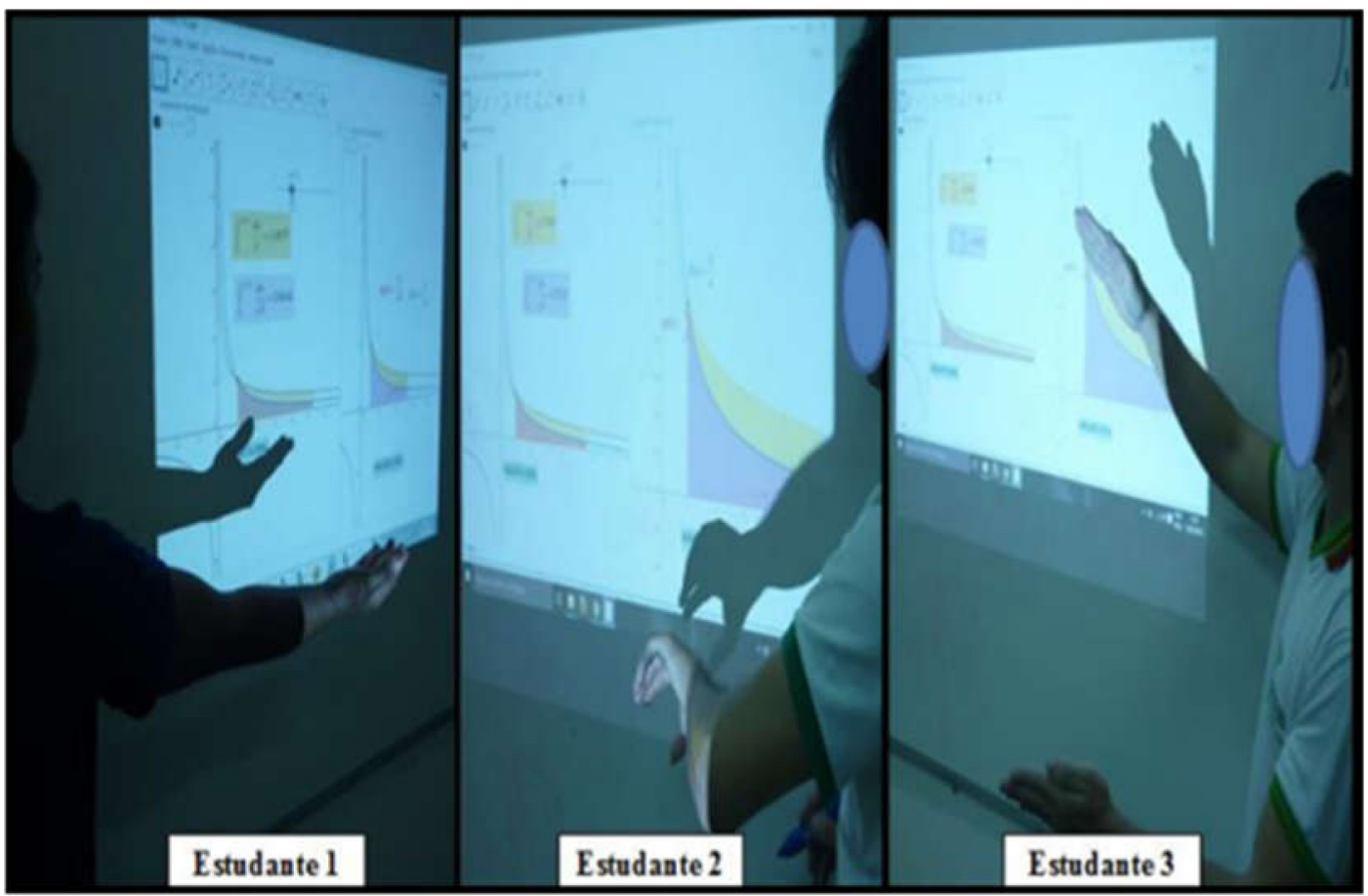

Figura 2. Descrição de um cenário de aprendizagem envolvendo a noção de Integral Generalizada e o papel dos gestos dos estudantes. 


\section{CONSIDERAÇõES FINAIS}

Nas seções predecessoras abordamos alguns elementos relacionados com o relevante tema comunicação no ensino e na aprendizagem em Matemática, todavia, a partir de um expediente que dedica maior atenção ao papel fundamental do professor de Matemática, com ênfase declarada pela mulficetada noção de competência profissional (Alves \& Acioly Régnier, 2020).

O papel da Didática Profissional DP, tendo em vista o estreito interesse pelo desenvolvimento humano, ao longo de sua vida profissional, proporciona uma perspectiva que relaciona a construção de experiências no trabalho e a aquisição idiossincrásica correspondente de variados recursos cognitivos. O binômio "desenvolvimento-aprendizagem" se mostra endereçado ao campo de formação dos adultos. Por conseguinte, a noção nominada de competência profissional coloca ênfase ao repertório de habilidades intrinsecas do individuo, diante da necessidade de se adaptar a um conjunto de situações profissionais, por vezes, inesperadas, caracteristicas para seu ofício.

Por outro lado, com origem em nossa discussão anterior, quando perspectivamos o trabalho dos professores de Matemática, sobretudo, o trabalho dos mais experientes (experts), podemos constatar que determinadas rotinas e dos roteiros de ação e execução tendem ou se dirigem a um processo de simplificação, optimização, estilo profissional lacônico e, até mesmo, de economia ou encurtamento das ações, não raro, o seu envelhecimento também. Claramente, divisamos alguns princípios da Ergonomia cognitivista, posto que, nos interessamos pelos roteiros de simplificação e não perda de eficiência de aplicação de conhecimentos e a competência exigida para tais tarefas. Por outro lado, ao passo que divisamos princípios ergonômicos que atuam diretamente na sua praxis em sala de aula, observamos, também, princípios organizadores da ação, perceptíveis por intermédio de gestos profissionais, em um contexto ampliado de exercício do ofício da docência e no campo do trabalho, todavia, requerem um maior estádio cientifico de compreensão.

Como indicamos há pouco, o papel imprescindível do funcionamento dos conceitos pragmáticos permeia um forte componente das relações laborais estabelecidas entre os sujeitos. No caso da Psicologia do Trabalho, podemos extrair várias repercussões para viuslumbrarmos a atividade e a competência do professor de Matemática. De fato, podemos registrar um conjunto de regras deondônticas, partilhadas pelos sujeitos (trabalhadores) que coabitam um determinado posto de trabalho (poste de travail). Observamos, entretanto, que existe um componente cognitivo capaz de explicar o reconhecimento de uma espécie de "contrato profissional" que, embora não disposto de forma oficial ou normativa, por intermédio de textos normativos ou diretivas, tais regras (implícitas) concorrem para a orientação e um princípio de esta- 
bilidade, identidade e se constitui como um fator da competência profissional, nesse caso, eventualmente, objetivado/compartilhado para todo um grupo e que confere sua identidade como um "gênero profissional" (genre profissionelles) comunicado por intermédio de linguagem e dos gestos.

Assinalamos que os pressupostos da DP proporcionam objetivarmos fenômenos estratégicos da atividade do professor de Matemática (Alves \& Acioly Régnier, 2020). De fato, quando tomamos como referência os fenômenos derivados das interações comunicativas envolvendo o binômio professor-estudantes, se espera que a linguagem, que a qualidade das informações e o conhecimento matemático seja transmitido com a maior qualidade possível, tendo em vista assegurar um itinerário adequado para a aprendizagem.

Por outro lado, quando tomamos como referência os fenômenos derivados das interações comunicativas envolvendo o binômio professor-professores, podemos registrar que as informações e modelos procedimentais da atividade docente ocorrem de modo cifrado, nem sempre de forma explícita. Neste segundo caso, urge comprender que a atividade situada do professor de Matemática não pode ser compreendida, de forma reducionista, somente no interior da sala de aula e, além disso, a comunição não se apresenta como um elemento fundamental apenas no ensino, quando objetivamos apenas os estudantes e, sim, as relações características envolvendo os binômios "professor-professores", "professor-pais de alunos" e, também, "professor-instituição escolar".

Por fim, cabe a compreensão de que não apresentamos uma discussão fimalizada e exaustiva sobre o tema "Comunicação no ensino e na aprendizagem", entretanto, se mostra imprescindível o amparo sistemático de outras teorias estruturantes e ramos científicos de estudos no Brasil ou em outros paises (Alves \& Catarino, 2019), tendo em vista o entendimento do papel, da atividade e do funcionamento do professor de Matemática no trabalho. Consequentemente, observamos que a habilidade de reconhecimento da função da linguagem matemática, tanto do compomente retórico, bem como do componente sintático (Jamison, 2000), do repertório gestual (profissional) incorporado pelo professor de Matemática se mostra indissociavelmente vinculado à qualidade de sua competência profissional e proporciona conferir uma espécie de !identidade profisssional" ao decurso do tempo.

\section{Agradecimentos}

Agradecemos ao apoio e suporte financeiro concedido no Brasil pelo Conselho Nacional de Desenvolvimento Científico e Tecnológico - CNPQ para o desenvolvimento dessa pesquisa no Brasil. 


\section{REFERÊNCIAS}

Alves, F. R. V. (2018). Didactique professionnelle (dp) et la théorie des situations didactiques (tsd): le cas de la notion d'obstacle et l'activité de professeur. Em Teia: Revista de Educação Matemática e Tecnológica Iberoamericana, 9(3), 1-26.

Alves, F. R. V. (2019). Didactique des mathématique (DM) et la didactique professionnelle (DP): une proposition de complementarité et la formation des enseignants au Brésil. Acta Scientarum Education, 41(1), 1-12. DOI: https://doi.org/10.4025/actascieduc.v43i1.50397.

Alves, F. R. V. (2020). Didactique professionnelle (didaprof): repercussão para a pesquisa em torno da atividade do professor de matemática. Revista Paradigma, 16(1), 1-54. DOI: 10.37618/PARADIGMA.1011-2251.0.p451-509.id881.

Alves, F. R. V. (2021). Transposition didactique et la transposition professionnelle: une discussion sur la notion de compétence du professeur de mathématiques. Revista Diálogo Educacional, 21 (69), 1-25.

Alves, F. R. V. \& Acioly Régnier, N. M. (2020). Ensino de Ciências e Matemática no Brasil: implicações da vertente francesa da Didática Profissional (DP) e a noção de competência. Indagatio Didactica, 12(5), 287308. DOI: https://doi.org/10.34624/id.v12i5.23478.

Alves, F. R. V. \& Catarino, P. M. (2019). Situação didática profissional: um exemplo de aplicação da didática profissional para a pesquisa objetivando a atividade do professor de Matemática no Brasil. Indagatio Didactica, 11(1), 103-129.

Bucheton, D. \& Soulé, Y. (2009). Les gestes professionnels et le jeu des postures de l'enseignant dans la classe: Un multi-agenda de préoccupations enchâssées. Éducation \& Didactique, 3(3), 29-48.

Clot, Y. (1999). Le geste est-il transmissible? In Apprendre autrement aujourd'bui ? 10e entretiens de la Villette. Cité des sciences et de la Villette. Recuperado de: http:/ / www.citesciences.fr/francais/ala_cite/act_educ/education/apprendre/comma pprends_p6.htm.

Clot, Y. \& Faïta, D. (2000). Genre et style en analyse du travail. Concepts et méthodes. Travailler, 1(4), 7-42.

Clot, Y. \& Leplat, J. (2005). La méthode clinique en ergonomie et en psychologie du travail. Le travail humain, 68(1), 289-316.
Coulange, L., Jaubert, M. \& Lhoste, Y. (2018). Les gestes professionnels langagiers didactiques dans différentes disciplines: fondements théoriques et méthodologiques - études de cas en mathématiques et en français. Ejournal de la recherche sur lintervention en éducation physique et sport, 2(43), 63-86.

Coulange, L. (2014). Les pratiques langagières au cœur de l'institutionnalisation des savoirs mathématiques. Spirale, 54(1), 9-27.

Jamison, R. E. (2000). Learning the Language of Mathematics. Language and Learning Across the Disciplines, 4(1), 45-54.

Joshua, S. y Dupin, J.-J. (1993). Introduction à la didactique des sciences et des mathématiques. París: Presses Universitaires de France - PUF.

Lima, M. V. (2017). Categorias intuitivas no ensino do cálculo e a visualização de critérios de convergência: o caso das Integrais dependentes de parâmetros - IDPs. (Dissertação de Mestrado). Fortaleza: Instituto Federal de Educação, Ciência e Tecnologia do Estado do Ceará, Brasil. Recuperado de http://pgecm.fortaleza.ifce.edu.br/wp-content/uploads/2017/06/ Disserta \%C3\%A7\%C3\%A3o-Final-Copia-DVD_ VANISIA.pdf.

Leplat, J. (2001). La gestion des communications par le contexte. Pistes, 3(1), 1-22.

Leplat, J. (2002). De l'étude de cas à l'analyse de l'activité. Pistes, 4(2), 1-34.

Leplat, J. (2004). Éléments pour l'étude des documents prescripteurs. Revue Activités, 1(2), 195-216.

Leplat, J. (2013). Les gestes dans l'activité en situation de travail. Pistes, 15(1), 1-24.

Machado, A. P. (2003). Do significado da escrita da Matemática na prática de ensinar e no processo de aprendizagem a partir do discurso de professores. (Tese de Doutorado). Rio Claro: UNESP, Brasil. Recuperado de: http://www.mariabicudo.com.br/resources/ TESES_e_DISSERTA $\%$ C3\%87\%C3\%95ES/ Ant $\%$ C 3 \% B 4nio $\% 20$ P $\%$ C 3 \% A 1 dua $\% 20$ Machado_T.pdf.

Margolinas, C. (2015). Situations, savoirs et connaissances... comme lieux de rencontre? Formation et pratiques d'enseignement en questions. 19(1), 31-39. 
Mayen, P., Olry, P. \& Pastré, P. (2017). L’ingénierie didactique professionnelle. In P. Carré, P. Caspar (2017), Traité des sciences et des techniques de la Formation (4e édition). Paris: DUNOD (pp. 467-482).

Pastré, P. (2001). Les compétences professionnelles et leur développement. La Revue de CFDT, 39.

Pastré, P. (2002). L'analyse du travail en didactique professionnelle. Revue Française de Pédagogie, 3(138), 9-17.

Pastré, P. (2007). Analyse du travail et formation. Recherceh et Education, 4(1), octobre, 23-29.

Pastré, P. (2011). La Didactique Professionelle. Education, Sciences \& Society, 2(1), 83-95.

Pastré, P., Mayen, P. \& Vergnaud, G. (2006). La didactique professionnelle. Revue Française de Pédagogie, 154(1), 1-55.

Radford, L. (2018). The emergence of symbolic algebraic thinking in primary school. In C. Kieran (ed.), Teaching and learning algebraic thinking with 5- to 12-year-olds: The global evolution of an emerging field of research and practice (pp. 3-25). Cham, Switzerland: Springer. doi:10.1007/978-3-319-68351-5_1.
Riccomini, P. J., Smith, G. W., Hughes, E. M. \& Fries, K. M. (2015). The language of Mathematics: The importance of teaching and learning mathematical vocabulary. Reading \& Writing Quarterly, 31(3), 235-252.

Robert, A. \& Rogalski, J. (2002). Le système complexe et cohérent des pratiques des enseignants de mathématiques: une double approche. Revue canadienne de l'enseignement des sciences, des mathématiques et des technologies, 2(4), 505-528.

Sensévy, G. (2005). Sur la notion de geste professionnel. La lettre de l'AiRDF, 1(36), 4-6.

Sonntag, M. (2002). Le schéma d'action: outil de figuration des représentations dans l'analyse des pratiques professionnelles. Revue Française de Pédagogie, 4(138), janvier, 29-38.

Terraneo, F. \& Avvanzino, N. (2006). Le concept de compétence en regard de l'évolution du travail: définitions et perspectives. Recherche en soins infirmiers, 5(87), 16-24.

Vergnaud, G. (2007). Les compétences en milieu professionnel. Journée d'étude Formation de Formateurs, 1(1), 1-6.

Veillard, L. (2012). Construire des curriculums d'apprentissage en situation de travail. Éducation \& Didactique, 6(1), 47-68.

Vieira Alves, F. R., y Acioly-Régnier, N. M. (2021). Comunicação no ensino, na aprendizagem e na atividade profissional do professor de Matemática: implicações da Didática Profissional (DP). IE Revista de Investigación Educativa de la REDIECH, 12, e1113. doi: 10.33010/ie_rie_rediech.v12i0.1113. 